\title{
Hacia una tipología de conflictos socioambientales en hidroeléctricas: experiencias de casos mexicanos y colombianos
}

\author{
Towards a typology of environmental conflicts due to \\ hydroelectric plants: experiences from Mexican and \\ Colombian cases
}

Rumo a uma tipologia de conflitos socioambientais em hidrelétricas: experiências de casos mexicanos e colombianos

Iván Mézquita Alonso* , Laura Celina Ruelas Monjardín** y Noé Hernández Cortez ${ }^{* * *}$

\begin{abstract}
RESUMEN
La construcción de presas es y ha sido severamente cuestionada por los impactos sociales, económicos y ambientales. El auge que experimentaron entre 1947 y 1960 disminuyó en las dos décadas siguientes. Sin embargo, ante el agotamiento de energías fósiles, se prevé un repunte de esta infraestructura. Ello ha llevado a ocurrir movilizaciones sociales y conflictos socioambientales. Dado que los conflictos no son fenómenos homogéneos, sino que dependen de factores como la participación ciudadana, es necesario conocer en qué medida los procesos participativos influyen en los conflictos socioambientales en torno a la cons-
\end{abstract} Palabras clave: gobernanza, participación ciudadana, presas.

\footnotetext{
* Maestrante en Desarrollo Regional Sustentable en El Colegio de Veracruz, Xalapa, Veracruz, México. E-mail: mezquita_alivan@hotmail.com

** Postdoctorado por la Universidad de British Columbia, Canadá. Profesora/Investigadora, Instituto Tecnológico Superior de Xalapa, Xalapa, Veracruz, México. E-mail: laura.rm@xalapa.tecnm.mx

*** Doctorado de Investigación en Ciencias Sociales con mención en Ciencia Política por la Facultad Latinoamericana de Ciencias Sociales, FLACSO, Sede México. Docente Investigador de Tiempo Completo Titular "C" en la Unidad Académica de Ciencia Política de la Universidad Autónoma de Zacatecas, Zacatecas, México. E-mail: noe.hernandez@uaz.edu.mx
} 
trucción de infraestructura hidroeléctrica. Así, el objetivo de este trabajo es proponer una tipología de conflictos socioambientales que considere la influencia de la participación ciudadana en torno a la construcción de infraestructura hidroeléctrica, tomando como criterio que los conflictos pueden ir, en graduación sucesiva, desde sencillos desacuerdos sin mayor repercusión social hasta la violencia, involucrando grandes conglomerados. Se analizaron estudios de caso de México y Colombia. Entre los resultados más sobresalientes, se encontró que en los procesos de gestión para la construcción de las hidroeléctricas, en ambos países se presentaron procesos viciados por engaños, manipulaciones y chantajes por parte de las autoridades y de las empresas a cargo de los proyectos.

\begin{abstract}
Dam constructions have always seen defiance from social, economic, and environmental forces. The boom they experienced between 1947 and 1960 subsided in the following two decades. However, with fossil fuel depletion, this infrastructure is expected to rebound, leading to social mobilizations and socio-environmental conflicts. Since conflicts are not homogeneous phenomena but rather depend on citizen participation, it is necessary to know the extent to which participatory processes influence socio-environmental conflicts around hydroelectric infrastructure construction. Thus, the objective of this work is to propose a typology of socio-environmental conflicts that considers the influence of citizen participation around the construction of hydroelectric infrastructure, taking as a criterion that the conflicts can go, in successive graduations, from simple disagreements without significant social repercussions to violence, involving large conglomerates. Case studies from Mexico and Colombia were analyzed. In both countries, management invested in hydroelectric plant constructions were involved in schemes of deception, manipulation, and blackmail joined by authorities and companies in charge of the projects.
\end{abstract}

\section{RESUMO}

A construção de barragens é e tem sido severamente questionada por seus impactos sociais, econômicos e ambientais. O auge experimentado entre 1947 e 1960 diminuiu nas duas décadas seguintes. Porém, com o esgotamento dos combustíveis fósseis, espera-se a retomada desta infraestrutura. Isto tem levado à ocorrência de mobilizações sociais e de conflitos socioambientais.
Keywords: governance, citizen participation, dams.

Palavras-chave: governança, participação cidadã, barragens. 
Como os conflitos não são fenômenos homogêneos, mas que dependem de fatores como a participação cidadã, é necessário saber até que ponto os processos participativos influenciam os conflitos socioambientais em torno da construção de infraestrutura hidrelétrica. Assim, o objetivo deste trabalho é propor uma tipologia de conflitos socioambientais que considere a influência da participação dos cidadãos em torno da construção de infraestrutura hidroelétrica, tomando como critério que os conflitos podem englobar, em graduação sucessiva, desde simples desentendimentos sem grandes repercussões sociais até a violência, envolvendo grandes conglomerados. Foram analisados estudos de caso do México e da Colômbia. Entre os resultados mais notáveis, verificou-se que nos processos de gestão para a construção de usinas hidrelétricas, em ambos os países ocorreram processos viciados por enganos, manipulações e chantagens por parte das autoridades e das empresas responsáveis pelos projetos. 


\section{Introducción}

La proliferación de presas en Europa, Estados Unidos de América y posteriormente en el resto del mundo, se ha convertido en uno de los retos hacia la naturaleza por parte del hombre (Tozoglu, 2020). A pesar de sus altos costos financieros y ambientales, sus supuestos beneficios aún son inciertos (Ansar, Flyvbjerg, Budzier \& Lunn, 2014). Aunque la infraestructura de presas a nivel mundial tuvo su auge en la década de 1950 cuando se construyeron casi el $90 \%$ de las grandes presas (Khargram, 2003), con el cambio climático y la demanda de energía que se proyecta se incrementará, se espera que este boom regrese. En Latinoamérica, las construcciones hidroeléctricas han sido parte de las políticas de desarrollo nacional y regional, y han sido orientadas a promover el crecimiento económico de las regiones marginadas (Barabas \& Bartolomé, 1992). Para el año 2016, la base de datos Global de Embalses y Presas de la Organización de las Naciones Unidas para la Alimentación y la Agricultura (2016), registraba 14.550 presas. De las cuales, México aparece con 100 y Colombia con 47.

De hecho, Colombia es uno de los países donde la mayor parte de su fuente de energía proviene principalmente de energía hidroeléctrica. Esta representa más del $64 \%$ de su generación total derivado de su actual política energética y es atractiva para empresarios interesados en la generación de dicha fuente de energía (Dussán Calderón, 2017). Esto, a pesar de que el número e intensidad de los conflictos socioambientales aumentaron durante la última década, principalmente por actividades extractivas, de desarrollo y construcción de grandes obras de infraestructura como las hidroeléctricas (Galvis \& Salazar, 2013).

En México, la construcción de seis grandes hidroeléctricas, que en su momento fueron consideradas de las más grandes de América Latina, se dieron entre 1947-1960, periodo considerado de auge mundial de las grandes presas. Si bien en las siguientes dos décadas, 1960-1980, se dio una disminución en la construcción de dicha infraestructura debido a los impactos ambientales y sociales que generan, en los últimos años la infraestructura hidroeléctrica ha ido en aumento al ser considerada una forma de generación de energía "limpia" (Ruelas, 2013) a diferencia de aquellas provenientes de combustibles fósiles (petróleo, carbón y gas).

En México, durante 2015, la generación de energía eléctrica renovable representó el 15,3\% (equivalente a 47.548,7 GWh) del total nacio- 
nal. De las hidroeléctricas construidas, al cierre de 2015, su generación se contó con una capacidad de $12.488,5 \mathrm{MW}$, de la cual, el 25,4\% proviene a cinco grandes presas: Aguamilpa, El Cajón, Huites, Zimapan y La Yesca. (Secretaría de Energía, 2016)

Los procesos de construcción de infraestructura hidroeléctrica se caracterizan por una toma de decisión vertical que no considera a las comunidades afectadas por el desarrollo de dichas construcciones. A pesar de que involucran un número relativamente grande de personas con diferentes objetivos, intereses, disciplinas y antecedentes ideológicos, se realizan aún con el efecto negativo en el medio ambiente y social, por lo que se ha convertido en uno de los temas más controvertidos en relación con el agua (Kishor Mahato \& Ogunlana, 2011). Ante dichos efectos, la generación de conflictos ha ido en incremento, entendiendo como conflicto a una situación social donde un mínimo de dos partes pugna por el mismo recurso y asumiendo que es una situación consustancial de las relaciones sociales y no necesariamente algo negativo. También debe tomarse en cuenta que el conflicto de intereses es un componente clave de las personas y sociedades, por lo que puede verse como una oportunidad para el cambio y motor del mismo (Ortiz, 1999).

Otros autores como Sager (1994) consideran que el conflicto es un componente esencial de una sociedad libre, el cual no surge de manera automática ante cierto problema. Por lo tanto, es visto como un constructo social que requiere de ciertas condiciones sociales para hacer de la protesta una condición social y no individual y aislada (Agüero, 2010), por lo que, si se gestiona adecuadamente, posibilita arreglos sociales que reducen el aislamiento de los individuos y generando mecanismos de cooperación (Ruelas, 2009).

Al ser los conflictos una realidad presente en toda la historia de la sociedad y la cultura humana, en el contexto de los recursos naturales, autores como Martínez-Alier (2004) los denominan como conflictos ecológico-distributivos, aludiendo a las condiciones económicas y políticas en las que riesgos y beneficios de la apropiación de bienes y servicios ambientales se distribuyen de forma desigual: mientras unos se llevan las ganancias, otros asumen los impactos negativos, poniendo énfasis en la distribución y los beneficios obtenidos del medio ambiente. Sin embargo, no todos los conflictos se pueden entender como "distributivos", 
ya que no en todos se disputa cómo se distribuyen los beneficios (Gudynas, 2014). También pueden manifestarse como políticos, sociales, económicos, étnicos, religiosos o conflictos territoriales, o como pugnas en torno a recursos o intereses nacionales. Son conflictos tradicionales inducidos por una degradación del ambiente (Homer-Dixon, 1991).

Para este trabajo retomamos la definición de Santos (2004), quien sostiene que si bien los conflictos socioambientales son espacios de confrontación, donde los diferentes actores involucrados manifiestan sus posturas, también son espacios de encuentro donde surgen alianzas y se tejen nuevas redes como estrategia de lucha. Aunque los conflictos ambientales no son fenómenos recientes, en los últimos años han tomado relevancia porque son expresiones de procesos sociales, políticos y ambientales (Paz Salinas, 2012), en los que la solución a problemas ambientales es esencialmente un problema de acción colectiva. Es por ello que la participación social es vista como un proceso de decisión formal donde los resultados dependen de los actos de más de un individuo (Coenen, 2008).

En este sentido, Ruelas, Chávez y Shaw (2009) señalan que los conflictos ofrecen la oportunidad para examinar temores y visiones sobre los problemas compartidos. En el caso específico del agua, se pueden convertir en una herramienta para la cooperación, la cual puede considerarse como acto necesario para su resolución. Para esto, la participación social contribuye a una óptima gestión del agua y es considerada como una estrategia que promueve el desarrollo sustentable en el ámbito local (Galvin \& Haller, 2008; Guerrero-de León, Gerritsen, Martínez-Rivera, Salcido-Ruíz, Meza-Rodríguez \& Bustos-Santana, 2010). Es por ello que, a mayor participación, mayor es la oportunidad para mejorar la gobernanza (Arnstein, 1969), la cual, de acuerdo con Carlsson y Sandström (2008), es una manera no centralizada de gobernar y se remite al proceso por el cual las políticas se van generando dentro de estructuras conformadas por nodos (actores) que están conectados a una multitud de vínculos, propiciándose así situaciones de cooperación (Mussetta, 2009). La idea de nueva gobernanza se asocia, en consecuencia, al involucramiento de la sociedad en los procesos de gobierno y se presenta como una forma no jerárquica de gobierno caracterizada por la cooperación con actores no estatales al interior de redes de decisión mixtas entre lo público y lo privado. 
$\mathrm{Al}$ ser un concepto polisémico, la gobernanza es utilizada desde diferentes disciplinas. En este contexto, podemos hablar de gobernanza ambiental, la cual se funda a partir del reconocimiento de las responsabilidades que tiene la sociedad para la protección y cuidado del medio ambiente mediante la existencia de un marco legal, de institucionalidad y de la participación del público en las decisiones en el nivel que corresponda (Valencia \& Garrido, 2018). En este sentido, en México se han creado mecanismos de gobernanza como los consejos de cuenca, donde su principal objetivo es fungir como una instancia de coordinación, concertación, apoyo, consulta, asesoría y como un mecanismo de solución y arbitraje de los conflictos que permiten formular y ejecutar programas y acciones con la finalidad de llevar a cabo una adecuada gestión del agua, lo que involucra el desarrollo de infraestructura, servicios y la preservación de los recursos de la cuenca (Ruelas, 2017).

La gobernanza, en términos del medio ambiente -como el manejo del agua- implica la participación de múltiples actores, la mayoría de las veces con metas contradictorias. Por esta razón, se retoma el artículo clásico sobre participación que propuso Arnstein (1969) hace varias décadas, pero que aún sigue vigente. La relación gobernanza y participación, en términos de Arnstein (1969), se realiza debido a que la buena gobernanza tiene que ver con la calidad de los procesos de toma de decisiones y el supuesto implícito o explícito de la escalera de la participación ciudadana, y es que a medida que los ciudadanos ascienden en la escalera, mejor participación en la toma de decisiones. En este paralelismo de la escalera, se señala que la participación no es un concepto homogéneo, sino que diferenciado, e implica derechos y obligaciones para los ciudadanos. Para ello, lo representa en forma de escalera, con ocho escalones, donde uno es una extensión del poder de los ciudadanos. Los primeros dos escalones se consideran de "no participación", esto es, de manipulación (1) y terapia (2); los escalones 3, 4 y 5 progresan a niveles de tokenismo, es decir a informar (3), consultar (4) y aplacar (5); el nivel 5, aunque es un nivel superior, todavía los que detentan el poder continúan con el derecho de decidir; en el escalón 6, a los ciudadanos se les permite negociar; finalmente, el escalón 7 corresponde al poder delegado y el 8 , al control ciudadano. Estas gradaciones permiten comprender en qué medida la participación social se involucra en la toma de decisiones y cuáles serían las obligaciones 
para los ciudadanos. Es más, el asunto no es solo arribar a este escalón máximo de participación, sino en cómo permanecer.

En los conflictos socioambientales, los procesos participativos presentan diversas perspectivas, como el conocimiento local y uso tradicional de los recursos, los cuales contribuyen a la generación de soluciones y apoyo en la toma de decisiones, como lo menciona Coenen (2008). Asimismo, el cumplimiento y la implementación son otros factores a destacar, que, de no ser llevados de buena forma, como el ser considerados injustos, pueden generar un conflicto de estancamiento donde la aceptación se ve disminuida y la implementación obstaculizada (Drazkiewicz, Challies \& Newig, 2015). En contraparte, al ser partícipes de un proceso justo, los involucrados fomentan la cooperación y desarrollo de alianzas y redes, generando un capital social basado en la confianza y normas compartidas (Leach \& Sabatier, 2005). La articulación y construcción de redes se posiciona como una parte fundamental de las estrategias organizativas viables y necesarias para la búsqueda de alternativas a las problemáticas socioambientales. Debido a que la sociedad actual es considerada mucho más compleja que aquella que la precedió en torno a los conflictos socioambientales por energía, donde la participación de expertos y legos es fundamental para contar con información y conocimientos pertinentes (VallejosRomero, Riquelme \& Garrido, 2017), independientemente de si el conflicto es latente o manifiesto, con el propósito de reaccionar ante los diferentes escenarios. (Skill, 2010)

Esta complejidad de la sociedad toma en consideración los términos de redes sociales, capital social y acción colectiva en el contexto del conflicto socioambiental, siendo la formación de las redes sociales con una estructura y propiedades determinadas la base para la generación del capital social y el posterior surgimiento de la acción colectiva (Fonseca, Montalba \& García, 2015), es decir, una estrategia de gobernanza. Putnam (1993) concibe al capital social como los aspectos de las organizaciones sociales, tales como las redes, normas y la confianza, dentro de una comunidad que facilitan la acción y la cooperación para un beneficio mutuo. Arosteguy (2007) identifica dos tipos de capital social, a saber:

Mientras tanto, Coleman señala que existen varios tipos de capital social. El primero es el capital social individual que consta del cré- 
dito acumulado de una persona en la forma de reciprocidad difusa que puede reclamar en momentos de necesidad, a otras personas para las cuales ha realizado, en forma directa o indirecta, servicios o favores en cualquier momento [...] El capital social comunitario o colectivo, en cambio, consta de normas y estructuras que conforman las instituciones de cooperación grupal [...] el capital social comunitario no es un recurso individual, sino una forma de institucionalidad social del conjunto y que los participantes de este capital se plantean como objetivo, en forma explícita o implícita, el bien común aunque no necesariamente lo alcanzan. (pp. 129-131).

En este orden de ideas, se sostiene que los conflictos socioambientales por la disputa de los recursos naturales no suelen ser exclusivamente antagónicos y excluyentes per se, sino que abren las posibilidades a la cooperación y la participación social. De hecho, la robusta literatura en torno a la participación social de Arnstein (1969) y el conflicto socioambiental de Langholz, Sand, Raak, Berner, Anderson, Geels, McKeehan y Nelsen (2013) suponen un común denominador: estrategias organizativas para canalizar el conflicto por la vía democrática para la participación de todos los interesados. De ahí, la relevancia del capital social, pues, se asume que a mayor participación social, más se fortalece el capital social de la comunidad por medio de la interacción social y entendimiento del conflicto, la deliberación pública y los lazos de confianza. Podemos argumentar con Coleman (1988) que el capital social es una estructura de normas sociales, expectativas y canales de información que hacen posible la cohesión de un grupo o comunidad. Así, el conflicto abre la ventana de oportunidad para la participación social y, por consiguiente, el fortalecimiento del capital social de una comunidad para resolver de forma colectiva y con espíritu democrático los antagonismos (Mandarano, Meenar \& Steins, 2010).

Saz Gil, Almaguer Kalixto y Gómez Quintero (2016) mencionan que existe una ventaja competitiva en las redes donde los actores están fuertemente conectados, entendiendo por red al "grupo de individuos que, en forma agrupada o individual, se relacionan con otros con un fin específico" (p. 130) y que estas pueden tener muchos o pocos actores; mientras que para

Ostrom (2010) la acción colectiva hace referencia a la iniciativa social que implica a más de un individuo que con su esfuerzo apoye 
para la obtención de un resultado determinado y, además, las decisiones de los individuos sobre sus acciones son interdependientes, porque cada uno considera las decisiones de los otros. (Fonseca et al., 2015, p. 582)

En términos de los conflictos por el agua, "la acción colectiva puede ser contenciosa, entendida desde la teoría de los movimientos sociales como aquella orientada a la protesta y a la presión reivindicativa en representación de los intereses compartidos (Tilly y Tarrow, 2007; Tarrow, 2011)" (Fonseca et al., 2015, p. 580)

De ahí la generación de movimientos sociales, la cual es la forma cómo los individuos se comunican, se ponen de acuerdo y se organizan para la defensa de una causa. En México existen aproximadamente 198 organizaciones dirigidas a la oposición de los proyectos de infraestructura hidroeléctrica, aportando valiosa información y asesorando mediante talleres, cuadernillos, folletos, etc. sobre cómo enfrentar dichos proyectos. (Toledo, Garrido \& Barrera-Basols, 2013)

De acuerdo con Drazkiewicz, Challies \& Newig (2015), uno de los grandes problemas es no considerar a la sociedad como suficientemente informada o competente para la toma de decisiones o que los problemas de índole ambiental son considerados demasiado complicados como para dejarlo solo en manos de decisiones de políticos. Bajo ese criterio, la participación social se considera relevante (Drazkiewicz, Challies \& Newig, 2015). Sin embargo, la participación social y los procesos abiertos favorecen la confianza y dan legitimidad. La finalidad es asegurar que las decisiones sean por medio de evidencia, considerando la experiencia de aquellos que serán beneficiados o afectados por estas decisiones, como lo mencionan Valencia y Garrido (2018), quienes afirman que la participación del público se materializa mediante el acceso a la información, la participación en la toma de decisiones y el acceso a la justicia, debido a que en muchos casos la protección al medio ambiente supera las posibilidades de la estructura administrativa de los estados y que por ello requiere de los ciudadanos un rol activo de cuidado y defensa que involucre tanto derechos como deberes.

Si bien la participación social juega un papel importante en la toma de decisiones, es necesario conocer en qué medida los procesos participativos impactan en los conflictos socioambientales en torno a la construcción de infraestructura hidroeléctrica. Así, el objetivo de este 
trabajo es proponer una tipología de conflictos socioambientales que considere la influencia de la participación social en torno a la construcción de infraestructura hidroeléctrica, tomando como criterios generales que los conflictos ambientales pueden ir, en graduación sucesiva, desde sencillos desacuerdos, sin mayor repercusión social, hasta la violencia, involucrando grandes conglomerados.

\section{Metodología}

\section{Área de estudio}

Para el presente trabajo las hidroeléctricas estudiadas se localizan en los estados de Nayarit, Guerrero, Sinaloa, Puebla, Jalisco, Veracruz, Oaxaca e Hidalgo, estados que, de acuerdo con Mézquita, Ruelas y Hernández (2018), seis de ellos se encuentran dentro de los estados con mayor número de hidroeléctricas en México (figura 1).

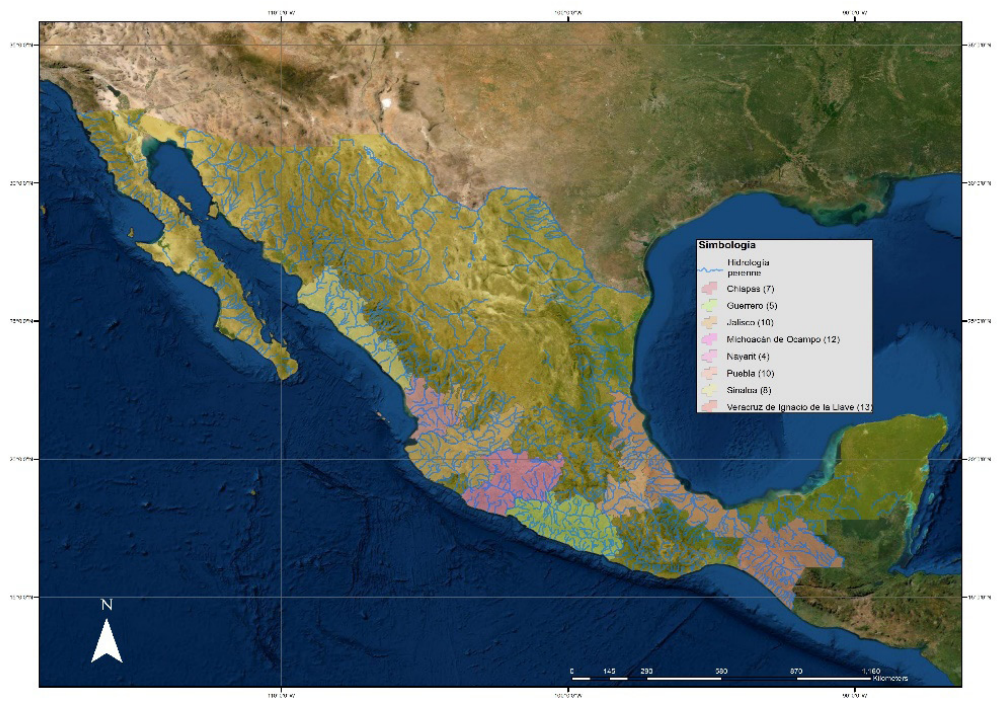

Figura 1. Estados con mayor número de hidroeléctricas en México. Fuente: Mézquita, Ruelas y Hernández (2018).

Para el caso de las hidroeléctricas en Colombia, El Quimbo se encuentra en el departamento del Huila, entre las cordilleras Central y Oriental, mientras que la hidroeléctrica de Monte Bonito se localiza en el oriente del departamento de Caldas (figura 2). 


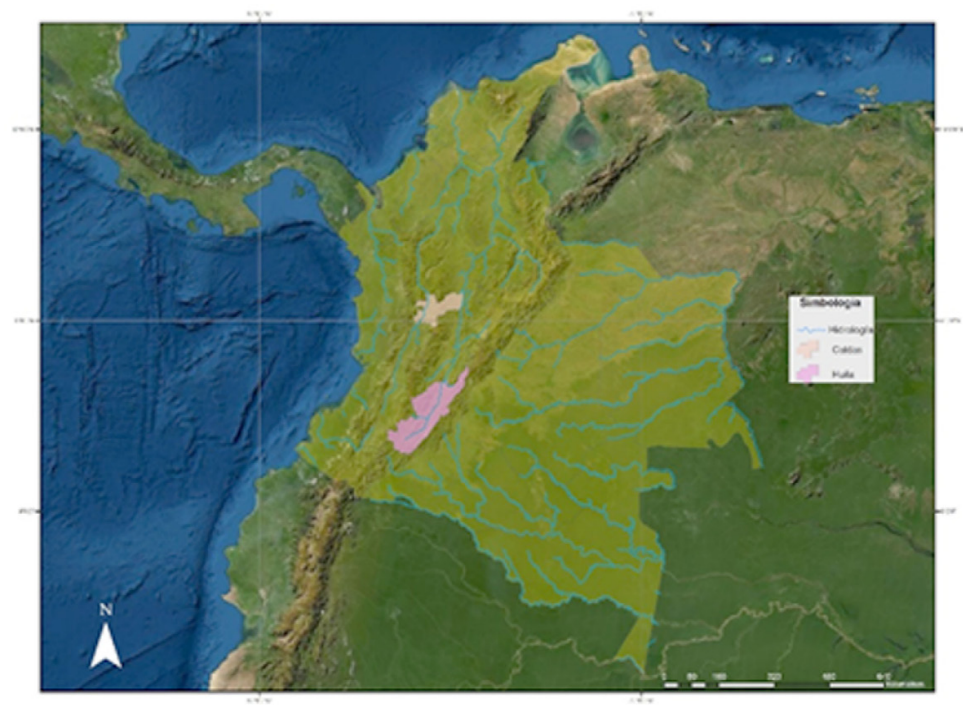

Figura 2. Ubicación de hidroeléctricas El Quimbo y Monte Bonito. Fuente: Elaboración propia.

\section{Métodos y técnicas}

Para la selección de los casos de estudio, se realizó una revisión previa de las hidroeléctricas con mayor relevancia respecto del proceso de su construcción. Para el caso mexicano, se incluyeron hidroeléctricas construidas cuyo estatus, de acuerdo con la Comisión Nacional del Agua (CONAGUA), se encuentran en operación, mientras que las clasificadas como inconclusas, es que no se logró su construcción. Esta clasificación de hidroeléctricas en México comprende los periodos de 1950-1970 y 1990-2010, correspondientes a los diferentes momentos relevantes de la construcción de hidroeléctricas a nivel nacional. Y para Colombia se tomaron como referencia una hidroeléctrica ya concluida con relevancia nacional y una en etapa de gestión de permisos ambientales.

Una vez seleccionadas las hidroeléctricas a estudiar, se identificaron aquellas características que reflejaran el nivel de participación ciudadana y la influencia de esta respecto al nivel de conflicto alcanzado. Para este análisis, se utilizaron las categorías de la escalera de participación de Arnstein (1969) que establece los niveles de participación ciudadana en la toma de decisiones (figura 3 ) y la tipología propuesta por Langholz et al. (2013) en la que se muestra el nivel de conflicto alcanzado de acuerdo con las características presentes en los casos de estudio (tabla 1). 


\begin{tabular}{l|l|l}
8 & Control ciudadano & \\
7 & Poder delegado & $\begin{array}{l}\text { Grados de } \\
\text { poder ciudad }\end{array}$ \\
6 & Asociación & \\
5 & Apaciguamiento & $\begin{array}{l}\text { Grados de } \\
\text { simbolismo }\end{array}$ \\
4 & Consulta & \\
3 & Información & No-participación \\
\cline { 2 - 3 } & Terapia & Manipulación
\end{tabular}

Figura 3. Escalera de participación de Sherry Arnstein. Fuente: Arnstein (1969).

Tabla 1

Tipología de niveles de conflicto de Langholz et al. (2013)

\begin{tabular}{|c|c|}
\hline ETAPAS & DESCRIPCIÓN \\
\hline $\begin{array}{l}\text { Etapa } 1 . \\
\text { Conflicto latente }\end{array}$ & $\begin{array}{l}\text { La degradación de los recursos, el acceso no equitativo a } \\
\text { los recursos u otras condiciones que pueden dar lugar a } \\
\text { conflictos. Esta etapa no siempre conduce a un conflicto } \\
\text { y de hecho puede estimular medidas preventivas, } \\
\text { incluido el desarrollo sostenible. }\end{array}$ \\
\hline $\begin{array}{l}\text { Etapa } 2 . \\
\text { Conflicto } \\
\text { emergente }\end{array}$ & $\begin{array}{l}\text { Los actores toman conciencia de la reducción de la } \\
\text { cantidad o calidad de los recursos naturales y se vuelven } \\
\text { descontentos. Los desacuerdos se expresan verbalmente } \\
\text { y normalmente de manera pacífica. }\end{array}$ \\
\hline $\begin{array}{l}\text { Etapa } 3 . \\
\text { Escalamiento de } \\
\text { conflictos }\end{array}$ & $\begin{array}{l}\text { Las tensiones y las hostilidades verbales aumentan y los } \\
\text { enfrentamientos de bajo nivel ocurren entre individuos o } \\
\text { grupos, incluyendo a veces actos de desobediencia civil. }\end{array}$ \\
\hline $\begin{array}{l}\text { Etapa } 4 . \\
\text { Conflicto (o } \\
\text { estancamiento) }\end{array}$ & $\begin{array}{l}\text { Se producen actos físicos, legales, económicos u otros } \\
\text { tipos de actos de confrontación (incluyendo violencia), } \\
\text { diseñados para mejorar el acceso o la calidad del recurso } \\
\text { natural en disputa. }\end{array}$ \\
\hline $\begin{array}{l}\text { Etapa } 5 . \\
\text { De escalada }\end{array}$ & $\begin{array}{l}\text { Los primeros pasos hacia la recuperación ocurren, } \\
\text { a menudo enfocados en rectificar una injusticia de } \\
\text { recursos naturales y frecuentemente a través de un } \\
\text { diálogo de consenso que incluye la búsqueda conjunta } \\
\text { de soluciones. }\end{array}$ \\
\hline $\begin{array}{l}\text { Etapa } 6 . \\
\text { Solución de } \\
\text { diferencias }\end{array}$ & $\begin{array}{l}\text { A través de medios legales, voluntarios y otros medios, las } \\
\text { partes desarrollan un plan de recuperación que incluye } \\
\text { corregir los errores anteriores de los recursos naturales y } \\
\text { prevenir los futuros. }\end{array}$ \\
\hline $\begin{array}{l}\text { Etapa } 7 . \\
\text { Recuperación }\end{array}$ & $\begin{array}{l}\text { Se centra en la aplicación y evaluación de soluciones } \\
\text { acordadas, a menudo haciendo hincapié en crear las } \\
\text { condiciones para una paz duradera, que se base en } \\
\text { los esfuerzos ambientales y económicos en forma de } \\
\text { desarrollo sostenible. }\end{array}$ \\
\hline
\end{tabular}

Fuente: Langholz et al. (2013). 
La recolección de datos fue mediante información hemerográfica en línea de circulación nacional y regional. Esto permitió representar la complejidad de estas situaciones sociales, además de la reconstrucción de las diferentes etapas del conflicto, los actores sociales y gubernamentales involucrados, así como el discurso público.

Para el contexto mexicano se hizo uso de prensa como La Jornada, Excélsior, La Prensa, La Razón, El Economista, Milenio, El Universal y Contralínea, mientras que para Colombia se revisaron diarios como: El Espectador, Agencia de Prensa Campesina (ANZORC), El Tiempo, La República, El Colombiano, El Espacio y Kien y Ke. Luego, con la información recopilada de prensa, se elaboró una base de datos a partir de la selección de los casos de relevancia referentes a la construcción de infraestructuras hidroeléctricas. La búsqueda se realizó de enero de 2017 a mayo de 2018. Una vez definidas las fuentes y el periodo de búsqueda de información, se definieron los criterios para seleccionar las notas que posteriormente fueron analizadas (tabla 2).

Tabla 2

Criterios de búsqueda

\begin{tabular}{clll}
\hline No & Criterio & Palabra clave 1 & Palabra clave 2 \\
\hline $\mathbf{1}$ & Manipulación & Presión & Obligar \\
\hline $\mathbf{2}$ & Terapia & Manejar & Engañar \\
\hline $\mathbf{3}$ & Información & Derechos & Comunicación \\
\hline $\mathbf{4}$ & Consulta & Reuniones & Entrevista \\
\hline $\mathbf{5}$ & Cooperación & Participación & Colaboración \\
\hline $\mathbf{6}$ & Asociación & Alianza & Coalición \\
\hline $\mathbf{7}$ & Negociación & Pacto & Convenio \\
\hline $\mathbf{8}$ & Control & Gestión & Garantía \\
\hline
\end{tabular}

Fuente: Elaboración propia.

Cada criterio de búsqueda se utilizó para cada caso de estudio en las diferentes publicaciones de prensa de circulación nacional y regional antes mencionadas. Una vez identificadas dichas características, se realizó una matriz donde se incluyó el nivel de conflicto alcanzado y el nivel de participación ciudadana. Dicho análisis fue realizado tanto en las hidroeléctricas construidas como en las que quedaron inconclusas en los casos mexicano y colombiano. 


\section{Resultados y discusión}

\section{Niveles de participación ciudadana en hidroeléctricas mexi- canas}

Conforme a los datos obtenidos de las hidroeléctricas construidas, el nivel de participación ciudadana de acuerdo con la escalera de participación de Arnstein (1969) corresponde a un 60\% en la categoría de manipulación, en la que la ciudadanía no posee una legítima función del poder decisorio, y $40 \%$ de terapia.

Las características principales de acuerdo con el nivel de participación ciudadana que se encontraron en cada caso de estudio se muestran en la tabla 3.

La manipulación se presentó en la mayoría de los casos, uno de los proyectos de mayor presencia en la prensa fue La Yesca, donde la característica de "amenazas para no reclamar pago por sus tierras" fue enunciado por los periódicos Excélsior y La Jornada, este último con 6 notas de prensa haciendo alusión a dicha característica.

Otras características comunes en la etapa de manipulación son "echar mano del chantaje, sobornos, compra de líderes y autoridades locales". En el caso de El Cajón, los medios de prensa El Universal y La Jornada hicieron mención a dicha característica con 4 y 3 notas respectivamente

Tabla 3

Nivel de participación ciudadana y principales características de hidroeléctricas construidas en México

\begin{tabular}{lll}
\hline Proyecto & $\begin{array}{l}\text { Nivel de participación } \\
\text { ciudadana }\end{array}$ & Características \\
\hline Aguamilpa & Manipulación & $\begin{array}{l}\text { No se realizan consultas } \\
\text { informadas. }\end{array}$ \\
\hline El Cajón & Manipulación & $\begin{array}{l}\text { Se echa mano del chantaje, } \\
\text { sobornos, compra de líderes y } \\
\text { autoridades locales. }\end{array}$ \\
\hline Huites & Terapia & Fraudes en asambleas ejidales. \\
\hline Zimapán & Terapia & $\begin{array}{l}\text { Evaluación del proyecto con la } \\
\text { comunidad, sin embargo no se les } \\
\text { explica nada. }\end{array}$ \\
\hline La Yesca & Manipulación & $\begin{array}{l}\text { Amenazas para disuadir de } \\
\text { reclamar el pago por sus tierras. }\end{array}$ \\
\hline
\end{tabular}

Fuente: Elaboración propia con base en la información hemerográfica. 
En el nivel de manipulación, a la ciudadanía se le cancela su legítima función del poder decisorio, de acuerdo con Kishor Mahato y Ogunlana (2011) las personas afectadas necesitan la aclaración respecto al beneficio del proyecto e informar cuando las decisiones afecten sus vidas.

En estos casos, al no existir una participación en la toma de decisiones por la falta de acceso a la información, se imposibilita la vía hacia la justicia, la cual, como mencionan Valencia y Garrido (2018), es clave para la materialización de la participación efectiva y poder involucrarse en un rol activo de cuidado y defensa. La debilidad de la participación ciudadana tiene como consecuencia el déficit democrático en la toma de decisiones colectivas para el manejo de los bienes comunes.

En el caso de las hidroeléctricas inconclusas, predominó la categoría de "información" con un 40\%, seguido de un 30\% en las categorías de "manipulación” y "terapia” respectivamente.

Dentro de los medios de prensa consultados, son muy marcados los casos donde se presenta mayor atención sobre los conflictos. El periódico La Jornada junto con Milenio mostraron la mayor cantidad de notas respecto a la característica de "incumplimiento de la consulta pública y manipulación de documentos de asambleas" en el caso de Las Cruces, con 8 y 5 notas respectivamente.

Para el proyecto La Parota, La Jornada presentó 8 notas con respecto a la característica de "falsificación de firmas y documentos". El nivel de participación y sus características principales se muestran a continuación en la tabla 4. 
Tabla 4

Nivel de participación ciudadana y principales características de hidroeléctricas inconclusas en México

\begin{tabular}{|c|c|c|}
\hline Proyecto & $\begin{array}{l}\text { Nivel de } \\
\text { Participación } \\
\text { ciudadana }\end{array}$ & Características \\
\hline La Parota & Manipulación & $\begin{array}{l}\text { Se falsificaron firmas y documentos } \\
\text { haciéndolos parecer legales. }\end{array}$ \\
\hline Las Cruces & Manipulación & $\begin{array}{l}\text { Se manipularon e impusieron el orden } \\
\text { del día y asamblea de comuneros en } \\
\text { favor del proyecto, se incumplió con la } \\
\text { consulta a pueblos indígenas. }\end{array}$ \\
\hline El Naranjal & Terapia & $\begin{array}{l}\text { Aprobación de consejos consultivos } \\
\text { viciados. }\end{array}$ \\
\hline Atexcaco & Manipulación & Simulación de consultas. \\
\hline Puebla 1 & Terapia & Operaron trampas y mañas. \\
\hline $\begin{array}{l}\text { Ana, Boca, } \\
\text { Conde y } \\
\text { Diego }\end{array}$ & Información & $\begin{array}{l}\text { Acarreo de personas y no se contempla } \\
\text { la participación de mujeres y niños. }\end{array}$ \\
\hline Gaya & Información & $\begin{array}{l}\text { No se proporciona conocimiento exacto } \\
\text { sobre el proyecto y cómo los afectaría. }\end{array}$ \\
\hline San Antonio & Información & $\begin{array}{l}\text { Falta de información generalizada, } \\
\text { inquietud por posibles desalojos. }\end{array}$ \\
\hline Paso la Reina & Información & $\begin{array}{l}\text { Falta de información completa, precisa, } \\
\text { accesible e imparcial. }\end{array}$ \\
\hline El Arcediano & Terapia & $\begin{array}{l}\text { Se impide asistencia de personas que se } \\
\text { oponen al proyecto. }\end{array}$ \\
\hline
\end{tabular}

Fuente: Elaboración propia con base en información hemerográfica.

Durante el proceso en torno a la construcción de las hidroeléctricas, la etapa de información, si bien se encuentra peldaños arriba respecto a la etapa de terapia y manipulación, sigue siendo una etapa donde la participación es simbólica y no efectiva, y se les informa superficialmente de sus derechos y responsabilidades, lo cual impide que la influencia de la participación social incida sobre el proceso en la toma de decisiones, a diferencia del caso de la construcción de un trasvase del río Guarinó al río La Miel donde el conocimiento de la cuenca, mecanismos legales, educación jurídica y la movilización de actores se materializó en el proceso de participación mediante mecanismos de acción popular. (Munévar \& Valencia, 2015) 
Niveles de participación ciudadana en hidroeléctricas colombianas

En el caso de la construcción de la hidroeléctrica El Quimbo de Colombia, el nivel de participación se quedó en el primer peldaño de participación, donde las características más representativas se observan en la tabla 5.

Dentro de los medios electrónicos de prensa, con 12 notas, El Espectador es el que mejor tiene documentado el caso. La publicación ha manifestado los principales conflictos generados por dicho proyecto, donde las características de "campesinos solo como espectadores y amenazas de expropiación de predios" son las constantes, al igual que en el periódico El Tiempo, en el que mediante 8 notas se ha hecho énfasis en dichas características.

Tabla 5

Nivel de participación ciudadana y principales características de hidroeléctrica construida en Colombia

\begin{tabular}{lll}
\hline Proyecto & $\begin{array}{l}\text { Nivel de Participación } \\
\text { ciudadana }\end{array}$ & Características \\
\hline \multirow{2}{*}{ El Quimbo } & Manipulación & $\begin{array}{l}\text { Los campesinos solo son } \\
\text { espectadores. }\end{array}$ \\
& & $\begin{array}{l}\text { Amenazas de expropiación de } \\
\text { predios. } \\
\text { Desacuerdo con el proyecto } \\
\text { durante audiencia pública. }\end{array}$ \\
\hline
\end{tabular}

Fuente: Elaboración propia con base en información hemerográfica.

En la etapa de manipulación, las características principales fueron que, durante el conflicto, los campesinos no se sentían parte de los actores en la etapa de la toma de decisiones, siendo únicamente espectadores a la hora de negociar. Así fue reportado por el periódico El Tiempo. Se manifestaron presiones por parte de las autoridades, respaldando mediante las garantías al inversionista la capacidad de solicitar la expropiación de predios en el caso de que los pobladores no estuvieran de acuerdo con ponerlos en venta. En consecuencia, la sociedad se sintió excluida por el Estado en esta crisis social y por la violación de sus derechos.

Si bien se llevó a cabo una consulta pública que pudiera situar dicho proceso de participación en la categoría de "consulta", la sociedad no fue tomada en cuenta, a pesar de existir una negativa de un $80 \%$ 
para la construcción de la hidroeléctrica y que no importara, como menciona el investigador José Jairo González Arias, si los habitantes querían permanecer en las tierras donde nacieron sus hijos y construyeron su memoria y tejido social, pudiendo ocasionar un desplazamiento forzado (El Tiempo, 2008). A pesar de ello, la autoridad emitió la autorización de la licencia ambiental que permitió a la empresa llevar a cabo la construcción de la hidroeléctrica El Quimbo. En aquella ocasión, González Arias declaró al periódico El Tiempo que "nadie les preguntó si querían dejar las tierras donde nacieron, tuvieron hijos y construyeron su memoria y tejido social y, lo más grave es que podría generarse un desplazamiento forzado" (Quintero, 2008, s/p).

La manipulación dentro de los procesos participativos es la etapa que se presenta en la mayoría de los proyectos del extractivismo, para este caso, de acuerdo con Dussán Calderón (2014), la compañía impuso los términos y condiciones de la concertación y que fueron aceptadas por el gobernador, alcaldes, parlamentarios y gremios económicos en un proceso de corrupción, donde la Corte Constitucional señaló que "no se constata en el presente caso la existencia de un verdadero proceso de participación".

En este tipo de procesos, la proporción de información sobre los proyectos resulta ser insuficiente, como el caso de la hidroeléctrica HidroAysén en Chile, donde se presentó una desconfianza sobre cómo se transmitió la información, un ejemplo de que la comunicación deja de ser transversal y se pierde su eficacia. (Vallejos-Romero y Riquelme Guerrero, 2017)

Si bien la mayoría de la información recabada sobre El Quimbo es referida hacia el descontento de la sociedad por los impactos sociales y ambientales que se pueden generar, algunos columnistas de los periódicos han manifestado una opinión positiva respecto al proyecto. Juan Gómez Martínez del periódico El Colombiano (2012) menciona que la desinformación y el engaño son la base fundamental para mover a los campesinos a que se opongan a los proyectos que generan riqueza para Colombia.

Para el caso de Monte Bonito, en la tabla 6 podemos observar las principales características durante el proceso de gestión de la hidroeléctrica, tomando en consideración que el proceso sigue abierto. 
Tabla 6

Nivel de participación ciudadana y principales características de hidroeléctrica inconclusa en Colombia

\begin{tabular}{lll}
\hline Proyecto & $\begin{array}{l}\text { Nivel de Participación } \\
\text { ciudadana }\end{array}$ & Características \\
\hline & & $\begin{array}{l}\text { Manipulación de firmas a favor del } \\
\text { proyecto. }\end{array}$ \\
& & $\begin{array}{l}\text { Esfuerzos aislados por la población. } \\
\text { Audiencia pública con información }\end{array}$ \\
Bonte & Manipulación & a medias. \\
Bonito & & $\begin{array}{l}\text { Autoridades gubernamentales a } \\
\text { favor del proyecto, proporcionando } \\
\text { información engañosa y declarando } \\
\text { el proyecto como utilidad pública. }\end{array}$ \\
\hline
\end{tabular}

Fuente: Elaboración propia con base en información hemerográfica.

Si bien se ha llevado un proceso, como fue la audiencia pública y donde se documentó un involucramiento de la sociedad en la toma de decisiones, las acciones por parte de la empresa han estado viciadas, pues se manipularon firmas de asistencia, haciéndolas pasar por votos a favor del proyecto, y realizaron gestos de intimidación hacia propietarios de predios para la compra de sus tierras. Respecto de las autoridades, estas han ejercido una presión hacia la población, emitiendo un resolutivo donde declara el proyecto de Monte Bonito como de utilidad pública, lo cual permite la expropiación de tierras con el fin de llevar a cabo la construcción hidroeléctrica, considerándola necesaria por el beneficio de la sociedad.

Hay que mencionar que el proceso de gestión para llevar a cabo dichas obras se encuentra en proceso y a pesar de que en un inicio la empresa a cargo de la construcción no realizó una adecuada inclusión de la sociedad mediante el involucramiento de diversas organizaciones, se ha logrado que la sociedad se encuentre más informada y hasta el momento se sigan llevando modificaciones a la licencia ambiental autorizada por la autoridad ambiental.

Es importante destacar que la participación de organizaciones académicas, como la Clínica Sociojurídica de Interés Público y el Consultorio Jurídico de la Universidad de Caldas, las cuales tienen la función de identificar, fortalecer y acompañar los procesos de las comunidades involucradas en problemas y conflictos ambientales, prestando 
asesoría técnico-jurídica en defensa al derecho colectivo. Dicha participación ha generado que la sociedad se encuentre más involucrada en el proceso en torno a la construcción de la hidroeléctrica. Esto ha sido posible mediante la realización de talleres con la finalidad de mostrar cuáles son los mecanismos de participación ciudadana que pueden emplear para la defensa de sus derechos y acceso a la justicia ambiental. Estos mecanismos de participación, como mencionan Hevia, Vergara-Lope y Ávila Landa (2011), son una de las innovaciones significativas en los procesos de democratización en América Latina donde la academia se interesó por estos procesos desde diversas aproximaciones: unas centradas en el concepto de gobernanza y otras en la ampliación de los actores en el espacio público.

El éxito de dichos talleres se ve reflejado en la participación ciudadana y en poder aplicar dichos conocimientos. Ese es el caso de uno de los ciudadanos de la comunidad afectada, quien menciona que, si siguen con la idea de implementar el proyecto, le tocará ir a una consulta popular -un mecanismo normativo de participación ciudadana-, y no dejándose rendir, ya que, si bien ha sido muy difícil por ser una competencia injusta y donde hay mucho dinero de por medio, y no solo es luchar contra la empresa, sino también contra el gobierno. (Comunicación personal, mayo 28, 2018)

La importancia de la participación de diversas organizaciones, como mencionan Toledo et al. (2013), no solo es la resistencia de carácter defensivo que busca evitar la implantación de proyectos destructivos sino también el impulsar y realizar proyectos alternativos al modelo dominante. En el caso de México, la resistencia a los conflictos socioambientales ha quedado organizada en 8 redes que agrupan casi 300 organizaciones regionales.

Dichas organizaciones buscan la justicia ambiental, no obstante que se les presentan mayores obstáculos debido a la complejidad social, cultural y científico-técnica propia de los conflictos ambientales.

\section{Etapas del conflicto en hidroeléctricas en México}

A continuación, se presentan las etapas del conflicto alcanzado en torno a la construcción de infraestructura hidroeléctrica en México en casos donde dicha construcción llegó a culminarse (tabla 7). 
Tabla 7

Tipología de intensidad de conflictos en hidroeléctricas construidas en México

\begin{tabular}{|l|l|l|}
\hline Proyecto & Etapas & Acciones \\
\hline Aguamilpa & Escalamiento & $\begin{array}{l}\text { Violación de tratados internacionales de la } \\
\text { lista RAMSAR de marismas nacionales. }\end{array}$ \\
\hline Huites & Eajón & $\begin{array}{l}\text { Violación de derechos humanos, } \\
\text { desplazamiento forzoso, omisión de } \\
\text { derechos a la consulta, demagogia. }\end{array}$ \\
\hline Zimapán & Emergente & $\begin{array}{l}\text { Desplazamiento, expropiación de tierras, } \\
\text { engaños. }\end{array}$ \\
\hline La Yesca & Estancamiento & $\begin{array}{l}\text { Hosplazamiento, ejidatarios sin oposición. } \\
\text { daños a la salud, expropiación de tierras. }\end{array}$ \\
\hline
\end{tabular}

Fuente: Elaboración propia con base en información hemerográfica.

En los casos de las hidroeléctricas inconclusas, con respecto a los niveles de conflictos generados en torno a la construcción de infraestructura hidroeléctrica en México, el 50\% llegó a la etapa de estancamiento, $30 \%$ a emergente y $20 \%$ a escalamiento (ver tabla 8 ).

Tabla 8

Tipología de intensidad de conflictos en hidroeléctricas inconclusas en México

\begin{tabular}{lll}
\hline Proyecto & Etapas & Acciones \\
\hline La Parota & Estancamiento & Hostilidades y violencia. \\
\hline Las Cruces & Estancamiento & Actitudes agresivas. \\
\hline El Naranjal & Estancamiento & Disparos \\
\hline Atexcaco & Estancamiento & Presión, amenazas y manipulación. \\
\hline Puebla 1 & Estancamiento & $\begin{array}{l}\text { Violación de principios de leyes y } \\
\text { tratados internacionales. }\end{array}$ \\
\hline $\begin{array}{l}\text { Ana, Boca, } \\
\text { Conde y Diego }\end{array}$ & Emergente & Argumentos y análisis técnicos \\
\hline Gaya & Emergente & $\begin{array}{l}\text { Oposición de pobladores, junta de } \\
\text { firmas, SEMARNAT lo rechazó por } \\
\text { segunda vez. }\end{array}$ \\
\hline San Antonio & Emergente & $\begin{array}{l}\text { Comisión para el Diálogo de Pueblos } \\
\text { indígenas. }\end{array}$ \\
\hline Paso la Reina & Escalamiento & Engaños e intimidaciones \\
\hline El Arcediano & Escalamiento & Violación de derechos. \\
\hline
\end{tabular}

Fuente: Elaboración propia con base en información hemerográfica. 


\section{Etapas del conflicto en hidroeléctricas en Colombia}

A continuación, se presentan las principales acciones identificadas con respecto a las etapas del conflicto. En la tabla 9 se observa el proyecto hidroeléctrico El Quimbo cuyo proceso de construcción ha sido finalizado.

Tabla 9

Tipología de intensidad de conflictos en hidroeléctrica construida de Colombia

\begin{tabular}{lll}
\hline Proyecto & Etapas & Acciones \\
\hline \multirow{2}{*}{ El Quimbo } & Estancamiento & $\begin{array}{l}\text { Desalojos, violación de derechos sociales, } \\
\text { ambientales y económicos. } \\
\text { Manifestaciones, acciones de resistencia, } \\
\text { protestas y desobediencia civil. Ataque } \\
\text { por parte del ESMAD. } \\
\text { Intervención de las FARC. }\end{array}$ \\
\hline
\end{tabular}

Fuente: Elaboración propia con base en información hemerográfica.

Las acciones antes mencionadas se suman a lo documentado por el periódico El Colombiano, el que en 2012 menciona que manifestantes se enfrentaron con piedras al escuadrón policial quien recurrió a los gases lacrimógenos.

Durante el proceso de la construcción de la hidroeléctrica, se presentaron diversas acciones, tanto de las autoridades como de la sociedad, características de la etapa de estancamiento. Estas acciones se reflejaron mediante el desalojo de pobladores utilizando protocolos policiacos, ejerciendo el principio de autoridad. Dichas acciones hicieron sentir a la ciudadanía desplazada por el Estado, aludiendo a una crisis social por la violación de sus derechos sociales, ambientales y económicos. Asimismo, se utilizaron unidades de contraguerrilla de la policía en compañía del Escuadrón Móvil Antidisturbios (ESMAD) para proceder violentamente contra las comunidades que se manifestaron en las calles. Cabe mencionar que la creación de dicho escuadrón en 1999 respondió a la situación que atravesaba en ese momento y sigue atravesando el país, buscando el manejo y control de disturbios, Sin embargo, las acciones del ESMAD se han caracterizado por la violación a los derechos humanos, derechos político-sociales y al derecho internacional humanitario (Casas Ramírez, 2019). 
Lo antes mencionado desembocó en diversas manifestaciones por parte de pescadores, jóvenes y niños en las periferias del río Magdalena, impidiendo así la desviación de este. Estudiantes, indígenas y la comunidad en general llevaron a cabo manifestaciones en la ciudad, iniciando marchas desde la Universidad Surcolombiana hasta el centro de la ciudad. Dichas acciones llegaron a generar una desobediencia civil frente a la falta de defensa de sus derechos civiles y la violación a sus proyectos de vida.

Otro punto a destacar es la incorporación de actores relacionados a la guerrilla, como lo son las FARC, a quienes denominamos ecoterroris$\operatorname{tas}^{4}$ y quienes han hecho mención de que la patria es el río Magdalena. Este río corre peligro por el paso de las locomotoras santistas, proyectos de infraestructura financiados con capital transnacional. Si bien han manifestado su apoyo a la sociedad para evitar dichas construcciones, es bien sabido que están relacionados con actos de violencia política, por lo que su presencia y apoyo contra la hidroeléctrica se considera más como un fin político. A pesar de ello, su influencia sobre la sociedad civil es relevante, por lo cual son consideradas un actor clave.

A continuación, se muestra el caso del proyecto de Monte Bonito donde el nivel de conflicto se mantiene en la etapa emergente (ver tabla 10).

Tabla 10

Tipología de intensidad del conflicto de hidroeléctrica inconclusa en Colombia

\begin{tabular}{lll}
\hline Proyecto & Etapas & Acciones \\
\hline \multirow{2}{*}{ Monte Bonito } & Emergente & $\begin{array}{l}\text { Intimidaciones a dueños de predios. } \\
\text { Amenazas de expropiación de tierras. }\end{array}$ \\
\hline
\end{tabular}

Fuente: Elaboración propia con base en información hemerográfica.

Esta zona del país ha sido muy golpeada por las fuerzas armadas ilegales y donde diferentes grupos armados han tenido un impacto fuerte sobre la sociedad, por lo que muchas personas ante estos hechos permanecen a distancia ante las situaciones de conflictos, por lo que es un factor importante a la hora que la sociedad se involucre o no dentro de los procesos donde hay diversos intereses.

4 Molano-Rojas (2010) describe el ecoterrorismo como un método de violencia "para denunciar la contaminación y amedrentar a las empresas que desarrollan actividades nocivas para el medio ambiente o para algunas especies en peligro de extinción" (p. 238). 


\section{Propuesta de tipología con la influencia de la participación social}

En esta propuesta se retoman las etapas del conflicto alcanzadas en cada caso de estudio de México en las hidroeléctricas construidas y se incorpora el nivel de la participación ciudadana con sus características más representativas. En la tabla 11 podemos observar las hidroeléctricas donde el proceso de construcción se llevó a cabo, mientras que la tabla 12 contiene la información de los proyectos que quedaron inconclusos.

Tabla 11

Tipología de conflictos considerando la influencia de la participación social en proyectos construidos en México

\begin{tabular}{|c|c|c|c|}
\hline Proyecto & $\begin{array}{l}\text { Etapa del } \\
\text { conflicto }\end{array}$ & $\begin{array}{l}\text { Nivel de } \\
\text { Participación } \\
\text { ciudadana }\end{array}$ & Características \\
\hline Aguamilpa & Escalamiento & Manipulación & $\begin{array}{l}\text { Al ser el nivel de participación } \\
\text { más bajo del peldaño, la etapa del } \\
\text { conflicto logra llegar hasta tensiones } \\
\text { y hostilidades. }\end{array}$ \\
\hline El Cajón & Escalamiento & Manipulación & $\begin{array}{l}\text { Debido al bajo nivel de } \\
\text { participación efectiva, los chantajes } \\
\text { y sobornos generan una violación } \\
\text { a sus derechos, incluyendo el } \\
\text { desplazamiento forzoso. }\end{array}$ \\
\hline Huites & Emergente & Terapia & $\begin{array}{l}\text { Si bien el conflicto se mantuvo } \\
\text { en una etapa donde únicamente } \\
\text { se presentaron desacuerdos } \\
\text { verbales y de manera pacífica, } \\
\text { en gran medida fue debido a los } \\
\text { fraudes en las asambleas ejidales } \\
\text { los que permitieron conducir a los } \\
\text { ciudadanos mediante engaños. }\end{array}$ \\
\hline Zimapán & Emergente & Terapia & $\begin{array}{l}\text { Se utilizó la evaluación del proyecto } \\
\text { con la comunidad como forma } \\
\text { de participación ciudadana. } \\
\text { Sin embargo, no se les informó } \\
\text { oportuna y transparentemente, } \\
\text { generando la inexistencia de } \\
\text { una oposición por parte de los } \\
\text { ejidatarios ante el desconocimiento } \\
\text { del proyecto. }\end{array}$ \\
\hline La Yesca & Estancamiento & Manipulación & $\begin{array}{l}\text { Al pertenecer a la etapa de nivel de } \\
\text { participación más baja, el conflicto } \\
\text { llega al nivel más alto donde incluso } \\
\text { amenazas de muerte se hacen } \\
\text { evidentes, con nula intención de } \\
\text { tomar en cuenta a la sociedad. }\end{array}$ \\
\hline
\end{tabular}

Fuente: Elaboración propia con base en información hemerográfica. 
Tabla 12

Tipología de conflictos considerando la influencia de la participación ciudadana en proyectos inconclusos

\begin{tabular}{|c|c|c|c|}
\hline Proyecto & $\begin{array}{l}\text { Etapa del } \\
\text { conflicto }\end{array}$ & $\begin{array}{l}\text { Nivel de } \\
\text { Participación } \\
\text { ciudadana } \\
\end{array}$ & Características \\
\hline La Parota & Estancamiento & Manipulación & $\begin{array}{l}\text { Al no existir una legítima } \\
\text { función del poder decisorio, las } \\
\text { hostilidades y violencia son parte } \\
\text { de las acciones más comunes. }\end{array}$ \\
\hline Las Cruces & Estancamiento & Manipulación & $\begin{array}{l}\text { La omisión de la consulta a } \\
\text { pueblos indígenas, así como la } \\
\text { manipulación genera actitudes } \\
\text { agresivas al situarse en una } \\
\text { posición no favorable. }\end{array}$ \\
\hline El Naranjal & Estancamiento & Terapia & $\begin{array}{l}\text { Una etapa de conflicto donde la } \\
\text { violencia predomina y procesos } \\
\text { consultivos viciados. }\end{array}$ \\
\hline Atexcaco & Estancamiento & Manipulación & $\begin{array}{l}\text { No existe una participación } \\
\text { efectiva, lo que conlleva a la } \\
\text { generación de desacuerdos, } \\
\text { llegando a la presión y } \\
\text { manipulación hacia la sociedad. }\end{array}$ \\
\hline Puebla 1 & Estancamiento & Terapia & $\begin{array}{l}\text { Las trampas y mañas son un } \\
\text { recurso recurrente al momento de } \\
\text { informar a la ciudadanía. Como } \\
\text { consecuencia, la participación es } \\
\text { baja para ser considerada en la } \\
\text { toma de decisiones. }\end{array}$ \\
\hline $\begin{array}{l}\text { Ana, Boca, } \\
\text { Conde y } \\
\text { Diego }\end{array}$ & Emergente & Información & $\begin{array}{l}\text { El nivel de participación es bajo } \\
\text { debido a la información superficial } \\
\text { brindada, sin tomar en cuenta a } \\
\text { toda la población afectada. }\end{array}$ \\
\hline Gaya & Emergente & Información & $\begin{array}{l}\text { Se proporciona información } \\
\text { superficial a los ciudadanos. Sin } \\
\text { embargo, los pobladores están } \\
\text { conscientes de las afectaciones } \\
\text { que el proyecto generará. }\end{array}$ \\
\hline $\begin{array}{l}\text { San } \\
\text { Antonio }\end{array}$ & Emergente & Información & $\begin{array}{l}\text { Existe una inquietud natural ante } \\
\text { la falta de información; se buscan } \\
\text { alianzas para la defensa de sus } \\
\text { derechos (indígenas). }\end{array}$ \\
\hline $\begin{array}{l}\text { Paso la } \\
\text { Reina }\end{array}$ & Escalamiento & Información & $\begin{array}{l}\text { A pesar de que se proporciona } \\
\text { información, sigue sin ser } \\
\text { suficiente, aunado con las acciones } \\
\text { de engaños e intimidaciones por } \\
\text { parte de la empresa. }\end{array}$ \\
\hline $\begin{array}{l}\text { El } \\
\text { Arcediano }\end{array}$ & Escalamiento & Terapia & $\begin{array}{l}\text { El conflicto es manifiesto, pero } \\
\text { con posible aumento ante la } \\
\text { violación de derechos hacia la } \\
\text { ciudadanía, quienes están en } \\
\text { contra del proyecto. }\end{array}$ \\
\hline
\end{tabular}

Fuente: Elaboración propia con base en información hemerográfica. 
Tanto en las hidroeléctricas construidas como en las inconclusas se logra corroborar que el conflicto no es homogéneo, sino diferenciado, como señalan Ruelas, Chávez y Shaw (2009). Esto sucede porque se depende de ciertas características sociales para crear mecanismos de cooperación que generen resultados constructivos y no destructivos. En el caso de las hidroeléctricas inconclusas, las que presentaron un nivel de participación ciudadana más alto, el conflicto alcanzó a la etapa de escalamiento, mientras que donde el nivel de participación ciudadana llegó al primer peldaño de participación, el conflicto escaló hasta la etapa de estancamiento, que se caracteriza por presentar actos físicos e incluso violencia. Lo anterior nos indica que, a mayor nivel de participación ciudadana, menor nivel de conflicto alcanzado.

Una de las características principales para que un conflicto pueda llegar a los niveles de estancamiento no es precisamente el conflicto como tal, sino la rigidez de la estructura social durante los procesos participativos. Dichos procesos, como mencionan Munévar y Valencia (2015), no constituyen un capricho teórico. Las experiencias de casos exitosos de conflictos ambientales tienen como protagonistas la educación y la participación, materializadas en la movilización de la población en la protesta. Estos procesos no se llevaron a cabo en ninguno de los casos presentados, lo cual se refleja en los niveles de conflicto alcanzado, donde el estancamiento representa el 50\% y se caracteriza por presentar actos de confrontación incluyendo la violencia.

A continuación, se presenta la tipología de conflictos considerando la influencia de la participación ciudadana en los casos de estudio de las hidroeléctricas en Colombia (ver tablas 13 y 14). 
Tabla 13

Tipología de conflictos considerando la influencia de la participación ciudadana en hidroeléctrica construida

\begin{tabular}{llll}
\hline Proyecto & $\begin{array}{l}\text { Etapa del } \\
\text { conflicto }\end{array}$ & $\begin{array}{l}\text { Nivel de } \\
\text { Participación } \\
\text { ciudadana }\end{array}$ & Características \\
\hline El & Estancamiento & Manipulación & $\begin{array}{l}\text { El nivel de participación } \\
\text { ciudadana es bajo, que } \\
\text { pertenece al primer peldaño, } \\
\text { y el nivel de conflicto } \\
\text { alcanzado es el indeseable, } \\
\text { caracterizado por actos de } \\
\text { violencia y desobediencia } \\
\text { civil. }\end{array}$ \\
\hline
\end{tabular}

Fuente: Elaboración propia con base en información hemerográfica.

Tabla 14

Tipología de conflictos considerando la influencia de la participación ciudadana en hidroeléctrica en construcción

\begin{tabular}{llll}
\hline Proyecto & $\begin{array}{l}\text { Etapa del } \\
\text { conflicto }\end{array}$ & $\begin{array}{l}\text { Nivel de } \\
\text { Participación } \\
\text { ciudadana }\end{array}$ & Características \\
\hline $\begin{array}{l}\text { Monte } \\
\text { Bonito }\end{array}$ & Emergente & Manipulación & $\begin{array}{l}\text { Bajo nivel de conflicto y baja } \\
\text { participación ciudadana. Se } \\
\text { presentan manifestaciones } \\
\text { pacíficas en contra del proyecto. }\end{array}$ \\
\hline
\end{tabular}

Fuente: Elaboración propia con base en información hemerográfica.

En ambos casos el nivel de participación ciudadana fue bajo. Sin embargo, en el caso de El Quimbo, que ya es una hidroeléctrica construida, el conflicto alcanzó la etapa de estancamiento, mientras que Monte Bonito se encuentra en la etapa emergente, esperando que se dé fin al proyecto y que el nivel de conflicto no aumente.

Un factor importante que influye directamente en el nivel de participación en Colombia es el conflicto armado y la violencia, generando para las comunidades dificultades para su organización, representación y participación, una condición que aprovechan diversos actores para alcanzar intereses particulares, deslegitimando así los procesos de construcción colectiva y participativa.

Si bien se han llevado a cabo audiencias públicas donde los diferentes actores han manifestado sus diversas posturas, lo presentado por la 
empresa no coincide con los hechos. Acciones como la manipulación de firmas, intimidaciones a dueños de predios para que vendan sus propiedades y amenazas de expropiación avalado por las autoridades son factores que pueden generar que el conflicto escale hasta llegar al estancamiento, porque la sociedad considera que es un proceso injusto donde se violan sus derechos, por lo que el conflicto se manifiesta como destructivo.

\section{Conclusiones}

Los procesos de participación pueden tomar diferentes formas de acuerdo en los diferentes contextos, donde los objetivos y particularidades de cada caso pueden ayudar o afectar dichos procesos.

La intervención de actores con otros fines, como es el caso de fuerzas armadas ilegales, son actores que afectan la participación ciudadana en su involucramiento en conflictos socioambientales.

La influencia de la participación ciudadana en los procesos en torno a la construcción de infraestructura hidroeléctrica es proporcional a los niveles de conflictos alcanzados en dichos procesos. En los casos donde el nivel de conflicto llegó al estancamiento, la participación ciudadana, en la mayoría de los casos, se mantuvo en el primer peldaño de participación.

En los procesos de gestión para la construcción de las hidroeléctricas, tanto en México como en Colombia, se presentaron procesos viciados por engaños, manipulaciones y chantajes por parte de las autoridades y de las empresas a cargo de los proyectos.

Una de las principales limitantes en los procesos de participación es solo pensar en la ciudadanía como un ente al cual se le puede manipular y relegando a la participación solo como una opinión.

Las políticas en torno a la generación de energía eléctrica, tanto en México como en Colombia, han contribuido en gran medida a la construcción de infraestructura hidroeléctrica, permitiendo la entrada de capital privado para dichos proyectos. 


\section{Referencias}

Agüero, R. J. (2010). Entre las demandas reivindicativas y ambientales, conflictos por el agua en la zona metropolitana Córdoba-Orizaba, Veracruz, 1990-2006. Xalapa, México: Universidad Veracruzana.

Ansar, A., Flyvbjerg, B., Budzier, A. \& Lunn, D. (2014). Should we build more large dams? The actual costs of hydropower megaproject development. Energy Policy, 69, 43-56. doi: 10.1016/j.enpol.2013.10.069

Araujo, M. (14 de marzo de 2014). Problemas sociales y retraso en obras, vuelven a aplazar El Quimbo otros tres meses. La República. Recuperado de: https://www.larepublica.co/ economia/problemas-sociales-y-retraso-en-obras-vuelvena-aplazar-el-quimbo-otros-tres-meses-2104423 .

Arnstein, S. R. (1969). A ladder of citizen participation. Journal of the American Planning Association, 35(4), 216-224. doi: 10.1080/01944366908977225

Arosteguy, A. I. (2007). Construcción de capital social comunitario y empoderamiento ciudadano. Última década, 15(26), 123145. doi: 10.4067/S0718-22362007000100007

Barabas, A. \& Bartolomé, M. (1992). Antropología y relocalizaciones. Alteridades, 2(4), 5-15.

Calmard, D (13 de junio de 2017). Pueblos Náyeri y Wixárika reiteran oposición a hidroeléctrica Las Cruces en Nayarit. Proceso. Recuperado de: https://www.proceso.com.mx/nacional/estados/2017/6/13/pueblos-nayeri-wixarika-reiteran-oposicion-hidroelectrica-las-cruces-en-nayarit-186075.html .

Camacho, S. (17 de octubre de 2012). Afectados por presa exigen indemnización justa. La Jornada, p.23. Recuperado de: https:// www.jornada.com.mx/2012/10/17/politica/023n1pol

Carlsson, L. G. \& Sandström, A.C. (2008). Network governance of the commons. International Journal of the Commons, 2(1), 3354. doi: 10.18352/ijc.20

Casas Ramírez, D. A. (2019). Esmad, seguridad y posacuerdo: perspectivas sobre la protesta en Colombia. Ciencias Sociales y Educación, 8(16), 73-89. doi: 10.22395/csye.v8n16a5

Castellanos, L. (06 de noviembre de 2012). Denuncian ante TPP: presas desplazan a 185 mil personas. El Universal. Recuperado de: https://archivo.eluniversal.com.mx/estados/88546.html 
Castellanos, L. (09 de noviembre de 2012). Alertan violaciones por obras de presas. El Universal. Recuperado de: https://archivo. eluniversal.com.mx/estados/88601.html

Castro, S. G. (25 de septiembre de 2006). La presa El Cajón: un problema social, económico, politico, geológico y volcánico a punto de estallar. La Jornada Ecológica. Recuperado de: https://www. jornada.com.mx/2006/09/25/eco-f.html\#directora

Coenen, F. (2008). Public participation and better environmental decisions: the promise and limits of participatory processes for the quality of environmentally related decision-making. Enschede, Países Bajos: Springer Press.

Coleman, J. (1988). Social capital in the creation of human capital. The American Journal of Sociology, 94, S95-S120. Recuperado de https://www.jstor.org/stable/2780243

Del Castillo, A. (19 de diciembre de 2013). Acusan a la CFE y Nayarit de "engaños e intimidación". Milenio. Recuperado de: https:// www.milenio.com/estados/acusan-a-la-cfe-y-nayarit-deenganos-e-intimidacion .

Del Castillo, A. (06 de septiembre de 2016). Las Cruces, un proyecto "destructor" del ambiente. Milenio. Recuperado de: https:// www.milenio.com/estados/las-cruces-un-proyecto-destructor-del-ambiente .

Disturbios por desvío río y construcción de hidroeléctrica en Huila. (03 de marzo de 2012). El Colombiano. Recuperado de: https://www.elcolombiano.com/historico/disturbios_por_ desvio_rio_y_construccion_de_hidroelectrica_en_huilaKBEC_172293 .

Drazkiewicz, A., Challies, E. \& Newig, J. (2015). Public participation and local environmental planning: testing factors influencing decision quality and implementation in four case studies from Germany. Land Use Policy, 46, 211-222. doi: 10.1016/j. landusepol.2015.02.010

Dussán Calderón, M. A. (21 de abril de 2014). EMGESA desacata sentencia de la Corte Constitucional de Colombia. Recuperado de http:// millerdussan.blogia.com/2014/042101-emgesa-desacata-sentencia-de-la-corte-constitucional-de-colombia.php.

Dussán Calderón, M. A. (2017). El Quimbo: extractivismo, despojo, ecocidio y resistencia. Bogotá: Planeta Paz. 
Fonseca, F., Montalba, R. \& García, M. (2015). Redes sociales, capital social y acción colectiva en dos territorios campesinos de la región de La Araucanía, en Chile, para enfrentar problemas asociados al acceso al agua. Papers. Revista de Sociología, 100(4), 577-606. doi: 10.5565/rev/papers.2169

Galvin, M. \& Haller, T. (Eds.) (2008). People, Protected Areas and Global Change: Participatory Conservation in Latin America, Africa, Asia and Europe (Vol. 3). Berna: (NCCR) NorthSouth. Recuperado de https://www.researchgate.net/ publication/42760779_People_Protected_Areas_and_ Global_Change_Participatory_Conservation_in_Latin_ America_Africa_Asia_and_Europe

Galvis, M. C. \& Salazar, K. (2013). Derechos humanos y desarrollo económico: ¿Cómo armonizarlos? Anuario de Derechos Humanos, 9, 195-203. doi: 10.5354/0718-2279.2013.27044

Gudynas, E. (2014). Conflictos y extractivismos: conceptos, contenidos y dinámicas. Decursos, Revista en Ciencias Sociales, (27-28), 79-115. Recuperado del sitio Researchgate: https://www. researchgate.net/publication/326191722_Conflictos_y_extractivismos_conceptos_contenidos_y_dinamicas

Guerrero-de León, A. A., Gerritsen, P. R. W., Martínez-Rivera, L. M., Salcido-Ruíz, S. Meza-Rodríguez, D. \& Bustos-Santana, H. R. (2010). Gobernanza y participación social en la gestión del agua en la microcuenca El Cangrejo, en el municipio de Autlán de Navarro, Jalisco, México. Economía, Sociedad y Territorio, 10(33), 541-567. Recuperado de http://www. scielo.org.mx/scielo.php?script=sci_arttext\&pid=S1405$84212010000200009 \& \operatorname{lng}=$ es\&tlng=es.

Gómez, M. J. (07 de marzo de 2012). El Quimbo y los intereses. El Colombiano. Recuperado de: https://www.elcolombiano.com/ historico/el_quimbo_y_los_intereses-IBEC_172864 .

Hevia, F., Vergara-Lope, S. \& Ávila Landa, H. (2011). Participación ciudadana en México: consejos consultivos e instancias públicas de deliberación en el gobierno federal. Perfiles Latinoamericanos, 19(38), 65-88. Recuperado de http://www. scielo.org.mx/scielo.php?script=sci_arttext\&pid=S0188$76532011000200003 \& \operatorname{lng}=\mathrm{es} \& \ln \mathrm{l}=\mathrm{es}$.

Homer-Dixon, T. F. (1991). On the threshold: environmental changes as causes of acute conflict. International Security, 16(2), 76116. doi: $10.2307 / 2539061$ 
Khargram, S. (2003). Neither temples a global analysis nor tombs of large dams. Environment: Science and Policy for Sustainable Development, 45(4), 28-37. doi: 10.1080/00139150309604542

Kishor Mahato, B. \& Ogunlana, S. O. (2011). Conflict dynamics in a dam construction project: A case study. Built Environment Project and Asset Management, 1(2), 176-194. doi: 10.1108/20441241111180424

Langholz, J., Sand, K., Raak, L., Berner, A., Anderson, H., Geels, B., McKeehan, A. \& Nelsen, A. (2013). Strategies and tactics for managing environmental conflicts: insights from Goldman environmental prize recipients. Journal of Natural Resources Policy Research, 5(1), 1-17. doi: 10.1080/19390459.2013.771833

Leach, W. D. \& Sabatier, P. A. (2005). To trust an adversary: integrating rational and psychological models of collaborative policymaking. American Political Science Review, 99(4), 491-503. doi: 10.1017/S000305540505183X

Mandarano, L., Meenar, M. \& Steins, C. (2010). Building social capital in the digital age of civic engagement. Journal of Planning Literature, 25(2), 123-135. doi: 10.1177/0885412210394102

Martínez-Alier, J. (2004). Los conflictos ecológico-distributivos y los indicadores de sustentabilidad. Revista Iberoamericana de Economía Ecológica, 1, 21-30. Recuperado de https://www. raco.cat/index.php/Revibec/article/view/38278

Mézquita, I., Ruelas, L. C. \& Hernández, N. (2018). Conflictos socioambientales por construcción de hidroeléctricas: análisis de casos. En N. Hernández, L. C. Ruelas \& M. E. Nava (Coords.), Sustentabilidad del desarrollo: desafíos y propuestas (pp. 99112). Xalapa, México: Secretaría de Educación de Veracruz.

Méndez, E. (27 de septiembre de 2014). Alertan por proyecto hidroeléctrico en Nayarit. Excelsior. Recuperado de: https://www.excelsior.com.mx/nacional/2014/09/27/983912 .

Molano-Rojas, A. (2010). Aportes para una fenomenología del terrorismo: superando el problema definicional. Desafíos, 22(1), 226-249. Recuperado de https://revistas.urosario.edu.co/ index.php/desafios/article/view/1294

Munévar, C. \& Valencia, J. (2015). Origen y transformación del conflicto ambiental: análisis de los procesos de participación y edu- 
cación en dos estudios de caso. Civilizar. Ciencias Sociales y Humanas, 15(28), 47-60. doi: 10.22518/16578953.279

Mussetta, P. (2009). Participación y gobernanza. El modelo de gobierno del agua en México. Espacios Públicos, 12(25), 66-84. Recuperado de https://www.redalyc.org/pdf/676/67611350005.pdf

Organización de las Naciones Unidas para la Alimentación y la Agricultura. (s.f.). Aquastat [Base de Datos Sistema mundial de información de la FAO sobre el agua en la agricultura]. Recuperado de http://www.fao.org/nr/water/aquastat/data/ query/index.html?lang=es

Ortiz, P. (1999). Apuntes teórico-conceptuales para el diseño de una propuesta metodológica de manejo de conflictos socioambientales a través de la forestería comunitaria. En P. Ortiz (Comp.), Comunidades y conflictos socioambientales: experiencias y desafíos en América Latina (pp. 7-34). Quito: ABYA-YALA; Programa Bosques, Arboles y Comunidades Rurales FAO; COMUNIDEC. Recuperado de https://digitalrepository.unm. edu/cgi/viewcontent.cgi?referer=https://www.google.com/\& httpsredir=1\&article=1037\&context=abya_yala

Paz Salinas, M. F. (2012). Deterioro y resistencias. Conflictos socioambientales en México. En D. Tetreault, H. Ochoa García \& E. Hernández González (Coords.), Conflictos socioambientales y alternativas de la sociedad civil (pp. 27-47). Guadalajara: Instituto Tecnológico y de Estudios Superiores de Occidente. Recuperado de https://www.researchgate.net/publication/272171010_Conflictos_socio_ambientales_y_alternativas_de_la_sociedad_civil

Protesta contra El Quimbo. (02 de marzo de 2012). Kien y ke. Recuperado de: https://www.kienyke.com/confidencias/protestacontra-el-quimbo

Putnam, R. D. (1993). Making democracy work. Civic traditions in modern Italy. Princeton: Princeton University Press.

Quesada, C. (14 de Agosto de 2012). Fuerza de contraguerrilla y el Esmad atacaron a indígenas y campesino en El Quimbo. Agencia Prensa Rural. Recuperado de: https://prensarural.org/ spip/spip.php?article8881 .

Quintero, J. (23 de septiembre de 2008). Campesinos no venderán tierras para hidroeléctrica. El Tiempo. Recuperado de https://www. eltiempo.com/archivo/documento/MAM-3106138 . 
Ramírez, E. (15 de diciembre de 2010). El negocio de las represas. Contralínea. Recuperado de: https://www.contralinea.com.mx/ archivo-revista/2010/12/15/el-negocio-de-las-represas/ .

Ramírez, E. (08 de noviembre de 2012). Presas e hidroeléctricas: negocio y despojo. Contralínea. Recuperado de: https://www. contralinea.com.mx/archivo-revista/2012/11/08/presashidroelectricas-negocio-despojo/ .

Ruelas, L. C. (2013). Water management in Mexico: analysis from the sustainability perspective. En A. Yáñez-Arancibia, R. Dávalos-Sotelo, J. W. Day \& E. Reyes (Eds.), Ecological dimensions for sustainable socio economic development (pp. 69-86). Southampton: WIT Press.

Ruelas, L. C. (2017). Gobernanza para el manejo integral de cuencas. Xalapa, México: El Colegio de Veracruz; Juan Pablo Editor.

Ruelas, L. C., Chávez, J. M. \& Shaw, D. P. (2009). Scarcity and conflict, key problems in water management: a Mexican case study. Local Environment, 14(8),765-782. doi: 10.1080/13549830903102151

Sager, T. (1994). Communicative planning theory. Aldershot, England: Avebury.

Salazar, N. (03 de octubre de 2011). Crisis social por la represa El Quimbo genera protesta. El Espectador. Recuperado de: https:// www.elespectador.com/noticias/soyperiodista/crisis-social-represa-el-quimbo-genera-protesta-articulo-303283 .

Santos B. S. (2004). Democratizar la democracia. Los caminos de la democracia participativa. México D.F.: Fondo de Cultura Económica.

Saz Gil, I., Almaguer Kalixto, P. \& Gómez Quintero, J. D. (2016). Capital social y redes sociales: análisis del tercer sector en contextos rurales. CIRIEC-España, Revista de Economía Pública, Social y Cooperativa, (86), 123-154. Recuperado de https://ojs. uv.es/index.php/ciriecespana/article/view/8119

Secretaría de Energía. (2016). Prospectivas de energías renovables 20162030. Recuperado de https://www.gob.mx/cms/uploads/ attachment/file/177622/Prospectiva_de_Energ_as_Renovables_2016-2030.pdf

Skill, K. (2010). Investigar problemas ambientales en antropología social, pertinencia social y científica. Una aproximación al 
campo. Avá. Revista de Antropología, (18), 77-92. Recuperado de http://www.ava.unam.edu.ar/index.php/ava-18

Toledo, V. M., Garrido, D. \& Barrera-Basols, N. (2013). Conflictos socioambientales, resistencias ciudadanas y violencia neoliberal en México. Ecología Política, (46), 115-124.

Torres, B. B. \& Altamira, S. (30 de septiembre de 2013). Hidroeléctrica El Naranjal: por qué no darle luz verde. La Jornada Ecológica. Recuperado de: https://www.jornada.com.mx/2013/09/30/ eco-e.html .

Tozoglu, A. E. (2020). A chapter in the modernization of Turkey: damming the rivers, claiming the natural landscape, and building of the Seyhan Dam in Cilicia. Turkish Studies, doi: $10.1080 / 14683849.2020 .1746651$

Valencia, H. J. \& Garrido, J. (2018). Gobernanza ambiental, legalidad y participación ciudadana. En A. Vallejos-Romero, J. Valencia Hernández \& A. Boso (Eds.), Riesgos, gobernanza y conflictos socioambientales (pp. 131-151). Temuco: Universidad de La Frontera.

Vallejos-Romero, A., Riquelme, C. \& Garrido, J. (2017). Comunicación y conflictos socioambientales: una aproximación a la gobernanza de riesgos. Los casos de Castilla e HidroAysén en Chile. Perfiles Latinoamericanos, 25(49), 1-21. doi: 10.18504/ pl2549-005-2017 